\title{
Prefrontal and Monoaminergic Contributions to Stop-Signal Task Performance in Rats
}

\author{
Andrea Bari, Adam C. Mar, David E. Theobald, Sophie A. Elands, Kelechi C. N. A. Oganya, Dawn M. Eagle, \\ and Trevor W. Robbins \\ Department of Experimental Psychology and Behavioural and Clinical Neuroscience Institute, University of Cambridge, Cambridge CB2 3EB, United Kingdom
}

Defining the neural and neurochemical substrates of response inhibition is of crucial importance for the study and treatment of pathologies characterized by impulsivity such as attention-deficit/hyperactivity disorder and addiction. The stop-signal task (SST) is one of the most popular paradigms used to study the speed and efficacy of inhibitory processes in humans and other animals. Here we investigated the effect of temporarily inactivating different prefrontal subregions in the rat by means of muscimol microinfusions on SST performance. We found that dorsomedial prefrontal cortical areas are important for inhibiting an already initiated response. We also investigated the possible neural substrates of the selective noradrenaline reuptake inhibitor atomoxetine via its local microinfusion into different subregions of the rat prefrontal cortex. Our results show that both orbitofrontal and dorsal prelimbic cortices mediate the beneficial effects of atomoxetine on SST performance. To assess the neurochemical specificity of these effects, we infused the $\alpha 2$ adrenergic agonist guanfacine and the $\mathrm{D}_{1} / \mathrm{D}_{2}$ antagonist $\alpha$-flupenthixol in dorsal prelimbic cortex to interfere with noradrenergic and dopaminergic neurotransmission, respectively. Guanfacine, which modulates noradrenergic neurotransmission, selectively impaired stopping, whereas blocking dopaminergic receptors by $\alpha$-flupenthixol infusion prolonged go reaction time only, confirming the important role of noradrenergic neurotransmission in response inhibition. These results show that, similar to humans, distinct networks play important roles during SST performance in the rat and that they are differentially modulated by noradrenergic and dopaminergic neurotransmission. This study advances our understanding of the neuroanatomical and neurochemical determinants of impulsivity, which are relevant for a range of psychiatric disorders.

\section{Introduction}

Behavioral inhibition is the ability to exert executive control over behavior when environmental change requires the suppression of a prepotent response. This executive control is operationalized by tasks measuring the inhibition of a motor response, of which the stop-signal task (SST) is one of the most prominent. The stopsignal reaction time (SSRT) is a measure of the speed of the inhibitory processes derived from the SST (Logan, 1994) and is retarded in many pathologies characterized by impulsive behavior such as drug addiction, attention-deficit/hyperactivity disorder (ADHD), and schizophrenia and in patients with prefrontal cortex (PFC) damage (Aron et al., 2004; Feil et al., 2010; Lipszyc

Received March 27, 2011; accepted April 13, 2011.

Author contributions: A.B., A.C.M., D.M.E., and T.W.R. designed research; A.B., D.E.T., S.A.E., and K.C.N.A.O. performed research; A.B., A.C.M., S.A.E., and K.C.N.A.O. analyzed data; A.B., A.C.M., and T.W.R. wrote the paper.

Conflict of interest: T.W.R. discloses consultancy for Eli Lilly \& Co., Pfizer, Cambridge Cognition, and research grants from Lundbeck, Pfizer, and Eli Lilly \& Co.

This work was supported by Wellcome Trust Programme Grant 089589/Z/09/Z [awarded to T.W.R., B. J. Everitt, B. J. Sahakian, C. Roberts, and J. W. Dalley and completed within the University of Cambridge Behavioral and Clinical Neuroscience Institute (BCNI), supported by a joint award from the Medical Research Council and Wellcome Trust (Grant G0001354)]. A.B. was in receipt of a Medical Research Council PhD studentship awarded by the BCNI. We thank A. Lyon for technical assistance.

This article is freely available online through the J Neurosci Open Choice option.

Correspondence should be addressed to Andrea Bari, Department of Experimental Psychology, Behavioural and Clinical Neuroscience Institute, University of Cambridge, Downing Street, Cambridge CB2 3EB, UK. E-mail: andbari@gmail.com.

DOI:10.1523/JNEUROSCI.1543-11.2011

Copyright $\odot 2011$ the authors $\quad 0270-6474 / 11 / 319254-10 \$ 15.00 / 0$ and Schachar, 2010). More detailed knowledge of the neuroanatomical and neurochemical substrates of response inhibition in the rat would improve our understanding of the neural circuitries mediating behavioral and cognitive control.

Eagle et al. (2008b) found that rats with fiber-sparing lesions of the orbitofrontal cortex (OFC) had longer SSRTs, but no effects were observed after similar lesions of the prelimbic (PL) or infralimbic (IL) cortices (Eagle and Robbins, 2003b; Eagle and Baunez, 2010). However, there are still no data on the possible involvement of the rat anterior cingulate cortex (ACC) in SST performance, which was investigated in this study, together with other regions, using inactivation via muscimol microinfusion. Moreover, although evidence suggests an important contribution of norepinephrine (NE) neurotransmission in modulating prefrontal areas during response inhibition (Robbins and Arnsten, 2009), no evidence is yet available on the precise neural substrates in rodents, and this was the other main focus of this study.

Atomoxetine is a relatively selective NE reuptake inhibitor that increases extracellular availability of both $\mathrm{NE}$ and dopamine (DA) preferentially in PFC (Bymaster et al., 2002) and is approved for the treatment of ADHD (Faraone et al., 2005). Administration of atomoxetine improves SSRT in ADHD patients (Chamberlain et al., 2007) but also in normal rats (Robinson et al., 2008) and humans (Chamberlain et al., 2006). A recent pharmacological fMRI investigation in healthy volunteers showed that atomoxetine may work by modulating brain activity in ven- 

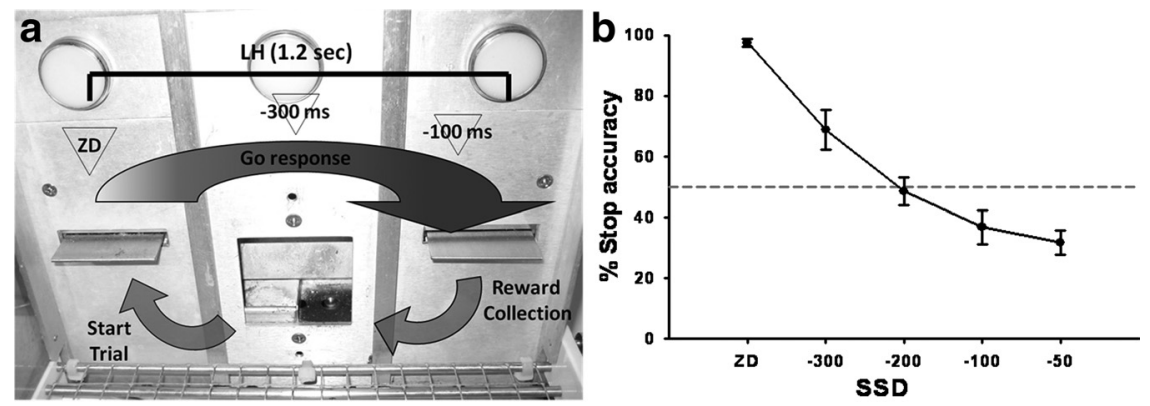

Figure 1. a, Schematic illustration of the SST structure. A standard session consists of 210 trials to be completed within $30 \mathrm{~min}$. On go trials ( $80 \%$ of total trials), the left and right levers have to be pressed in rapid sequence within the duration of the $L H(1.2 \mathrm{~s})$ to receive a reward, which is delivered in the central food well. On the remaining $20 \%$ of the trials (stop trials), an auditory stop signal will be played after the left lever has been pressed and after a variable SSD, which is calculated from each rat's mRT:ZD, mRT -300 and $-100 \mathrm{~ms}$. The presentation of the stop signal instructs the animal that the ongoing response to the right lever has to be inhibited to obtain the reward. Triangles represent the approximate time of presentation of the stop signal during the go response. $\boldsymbol{b}$, Representative inhibition function obtained by plotting the SSDs against the probability of successful response inhibition. SSDs for the experimental phase ( -300 and $-100 \mathrm{~ms}$ ) are chosen from the central part of the inhibition function, which is the most informative part both empirically and theoretically (Logan, 1994; Band et al., 2003).

trolateral PFC during stopping (Chamberlain et al., 2009), consistent with the involvement of this area in SST performance (Aron et al., 2004; Chambers et al., 2006). In the rat, it has been found that atomoxetine administration produces positive BOLD activation in the OFC (Easton et al., 2007) and increases fos-like immunoreactivity in medial PFC (Bymaster et al., 2002). However, the brain circuitries and receptors that are modulated by atomoxetine to decrease impulsivity in the rat are not yet known (Pattij and Vanderschuren, 2008).

In the present study, we investigated the neural substrates of response inhibition and the prefrontal sites modulated by atomoxetine in the mediation of its suppression of impulsivity. We then focused on one of the atomoxetine-sensitive sites to test whether the effects of atomoxetine are likely to be mediated by DA or NE. We used local infusions of the selective $\alpha 2$-adrenergic agonist guanfacine, to more selectively manipulate noradrenergic transmission, and of the mixed $\mathrm{D}_{1} / \mathrm{D}_{2}$ antagonist $\alpha$-flupenthixol, to block PFC DA transmission.

\section{Materials and Methods}

Subjects. A total of 120 male Lister-Hooded rats (Charles River) weighing $330-450 \mathrm{~g}$ at the time of the experiment was used. Rats were housed in groups of four under a reverse light/dark cycle (lights on 7:00 P.M. to 7:00 A.M.) and maintained at $85 \%$ of their free-feeding weight, with water available ad libitum. All experiments were conducted in accordance with the United Kingdom Animals (Scientific Procedures) Act, 1986.

SST training. Rats were trained on the SST following a procedure modified from Eagle and Robbins (2003a). Twelve operant chambers (Med Associates), each encased in a sound-attenuating box and fitted with two retractable levers located on either side of a food magazine, were used. Rats were initially trained to press the right lever (required force, $\sim 0.15 \mathrm{~N}$ ) to receive a reward pellet (Test Diet, $45 \mathrm{mg}$ precision-weight, purified ingredient rodent tablets; Sandown Scientific). The lever was then retracted, and collection of the reward in the food magazine started the subsequent trial with reintroduction of the right lever. Once the animals completed at least two consecutive daily sessions of 100 trials within $30 \mathrm{~min}$, they were presented with the left lever and learned to press it to extend the right one, which would result in the delivery of the reward if pressed within $30 \mathrm{~s}$ [limited hold (LH)]. The LH, the time available for the rats to press the right lever after pressing the left one, was progressively shortened until the rats reliably completed 100 trials with an LH of $5 \mathrm{~s}$. Stop trials were then introduced using an auditory stop signal $(4500 \mathrm{~Hz}, \sim 80 \mathrm{~dB}$ tone) that lasted from the left lever press until the end of the LH period, and the number of total trials was set to 210 . The $\mathrm{LH}$ and stop signal were made progressively shorter until they were kept constant for each animal. The final LH was $1.2 \mathrm{~s}$, and the stop-signal tone length was further shortened until it reached $100 \mathrm{~ms}$.

SST procedure. For all sessions, the task was initiated when the rats nose poked into the central food well. On go trials, the rats were rewarded with a food pellet for pressing the left followed by the right lever in fast sequence within the duration of the LH. If the rats failed to press the right lever before the end of the $\mathrm{LH}$, they received a timeout period (TO) (i.e., no reward, $5 \mathrm{~s}$ darkness, no levers available), and the trial was recorded as a go error. The latency of the go response [go reaction time (GoRT)] was defined as the time elapsed from the left to the right lever presses. Stop trials, presented on $20 \%$ of total trials, were pseudorandomly interspersed among go trials. Stop trials began in the same manner as a go trial, but after pressing the left lever, the animals were presented with the stop signal and were rewarded if they refrained from pressing the right lever for the duration of the LH. If the rats pressed the right lever after the stop-signal presentation, they were punished with a TO. During training, stop signals were presented immediately after the rats pressed the left lever [zero delay (ZD)]. During testing and for the calculation of the SSRT, stop signals were delivered at a predetermined delay [stop-signal delay (SSD)] after a left lever press. The different SSDs were presented in random order within the session.

Two baseline SST sessions were used to determine the inhibition function (Fig. 1) and to decide the best SSDs to use during the experimental phase: in these baseline sessions, rats were presented with four different SSDs [mean GoRT (mRT), $-300,-200,-100$, and $-50 \mathrm{~ms}$ ] and ZD. For test sessions, two SSDs were used and were calculated from the mRT averaged from three previous ZD sessions e.g., (mRT1 + mRT2 + $\mathrm{mRT} 3 / 3)-X \mathrm{~ms}=\mathrm{SSD}$, where " $-X \mathrm{~ms}$ " were chosen to produce on average $50 \%$ stop accuracy based on the inhibition function data and were -300 and $-100 \mathrm{~ms}$, plus ZD (Fig. 1). These SSDs capture the central part of the inhibition function, which is the most informative part both empirically and theoretically (Logan, 1994; Band et al., 2003). Control of the experimental chambers and online data collection were conducted using the Whisker control system (R. N. Cardinal and M. R. F. Aitken, 2001, Whisker computer software, version 2.2) and a customized software written in Visual Basic (by A. C. Mar).

Surgery. Rats were allocated to groups matched for baseline performance and chronically implanted with stainless-steel guide cannulae (28 gauge; Plastic One) aimed at the ACC, medial PFC, or ventrolateral OFC. We chose to target separately the ACC and dorsal PL (dPL) and ventral $\mathrm{PL} / \mathrm{IL}$ subfields of the medial PFC based on evidence of distinct corticocortical and cortico-subcortical connections. The dorsomedial sector (dmPFC) (encompassing both ACC and dPL) (Heidbreder and Groenewegen, 2003) mainly projects to motor and sensory areas but not limbic regions, whereas the ventromedial subdivision (vmPFC) has stronger connections with limbic and associative areas (Heidbreder and Groenewegen, 2003; Gabbott et al., 2005; Vertes, 2006; Hoover and Vertes, 2007).

For the surgical procedure, rats were anesthetized with isoflurane (4\% and reduced to $2 \%$ to maintain anesthesia) in oxygen and secured in a stereotaxic frame (David Kopf Instruments) fitted with atraumatic ear bars, with the incisor bar set at $-3.3 \mathrm{~mm}$ relative to the interaural line. Guide cannulae were implanted according to anteroposterior (AP), mediolateral (ML), and dorsoventral (DV) stereotaxic coordinates calculated from bregma and dura and taken from Paxinos and Watson (1998). They were as follows (in mm): ACC: AP, +2.5 ; ML, \pm 0.75 ; DV , -1.7 ; dPL and vmPFC: AP, +3 ; ML, \pm 0.75 ; DV, -2 ; OFC: AP, +3.2; ML, \pm 2.5 ; DV,-1.7 . Injectors were extended $1,1.5$, or $2 \mathrm{~mm}$ from the cannula tip to target the ACC/dPL, vmPFC, and OFC, respectively. Three or 
four small screws and cranioplastic cement were used to secure the guide cannulae in which removable obturators were inserted to prevent occlusion. Finally, a protective screw-on dust cap was secured on the guide cannulae. After surgery, animals were singly housed and left undisturbed for 5-7 d, before being retrained on the task.

Infusions. To habituate the animals to the infusion procedure, a mock infusion was performed $2 \mathrm{~d}$ before the start of drug testing. Animals received either drug or vehicle according to a randomized crossover design, allowing at least $2 \mathrm{~d}$ between infusions. Drugs were delivered bilaterally at a volume of $0.5 \mu \mathrm{l} / \mathrm{side}$, at a rate of $0.5 \mu \mathrm{l} / \mathrm{min}$ via polyethylene tubing $(0.28$ $\mathrm{mm}$ internal diameter, $0.16 \mathrm{~mm}$; Portex) connected to a $10 \mu \mathrm{l}$ Hamilton glass syringe that was mounted on an infusion pump (Harvard Apparatus). On test days, animals were gently restrained while the obturators were removed and stainless-steel injectors (22 gauge; Plastic One) were carefully inserted into the cannulae. Infusions started $1 \mathrm{~min}$ after the insertion of the injector, and, during infusions, the animals were left free to move on the lap of the experimenter. Efficacy of infusions was assessed by monitoring the movement of an air bubble along the infusion tubing. The injectors were left in place for additional $2 \mathrm{~min}$ to allow for diffusion into the surrounding tissue and were subsequently removed, and the obturators were replaced. Animals were then placed into the operant chamber, and the test started after an additional $1 \mathrm{~min}$. Only one infusion test day for each treatment was given.

Histology. Animals were killed with a lethal dose of pentobarbital ( $\sim 1.5 \mathrm{ml}$; Dolethal; Vetoquinol) and perfused transcardially with 0.01 M PBS, followed by $4 \%$ paraformaldehyde. Brains were removed, fixed for $24 \mathrm{~h}$ in $4 \%$ paraformaldehyde, and then dehydrated in $20 \%$ sucrose dissolved in 0.01 м PBS overnight. Coronal sections of $60 \mu \mathrm{m}$ thickness were obtained with a freezing microtome and mounted on glass slides, before being stained with cresyl violet for cannula placement verification. Anatomical landmarks were obtained from standard rat brain atlas images (Paxinos and Watson, 1998).

Experiment 1. Animals received intracerebral microinjections of either muscimol (0.5 $\mu \mathrm{g} / 0.5 \mu \mathrm{l}$ per side; Tocris Bioscience) or vehicle (sterile PBS) in ACC, dPL, vmPFC, or OFC. The same concentration of muscimol and similar infusion procedures have been used in previous studies (Corcoran and Maren, 2001; Souza et al., 2002; Kim and Ragozzino, 2005; Ragozzino and Rozman, 2007). Muscimol infusion causes fast and long-lasting reversible inactivation of neurons without affecting fibers of passage (van Duuren et al., 2007).

Experiment 2. Animals were microinjected with atomoxetine (Eli Lilly \& Co.) or its vehicle (sterile PBS) in ACC, dPL, vmPFC, or OFC. Atomoxetine was infused at the dose of $0.1 \mu \mathrm{g} / 0.5 \mu \mathrm{l}$ per side. This drug dose was chosen based on previous experiments (Bari et al., 2007).

Experiment 3. In this experiment, we modulated more selectively DA and NA in the dPL because infusions in this area resulted in significant effects in experiments 1 and 2. We chose to antagonize dopaminergic
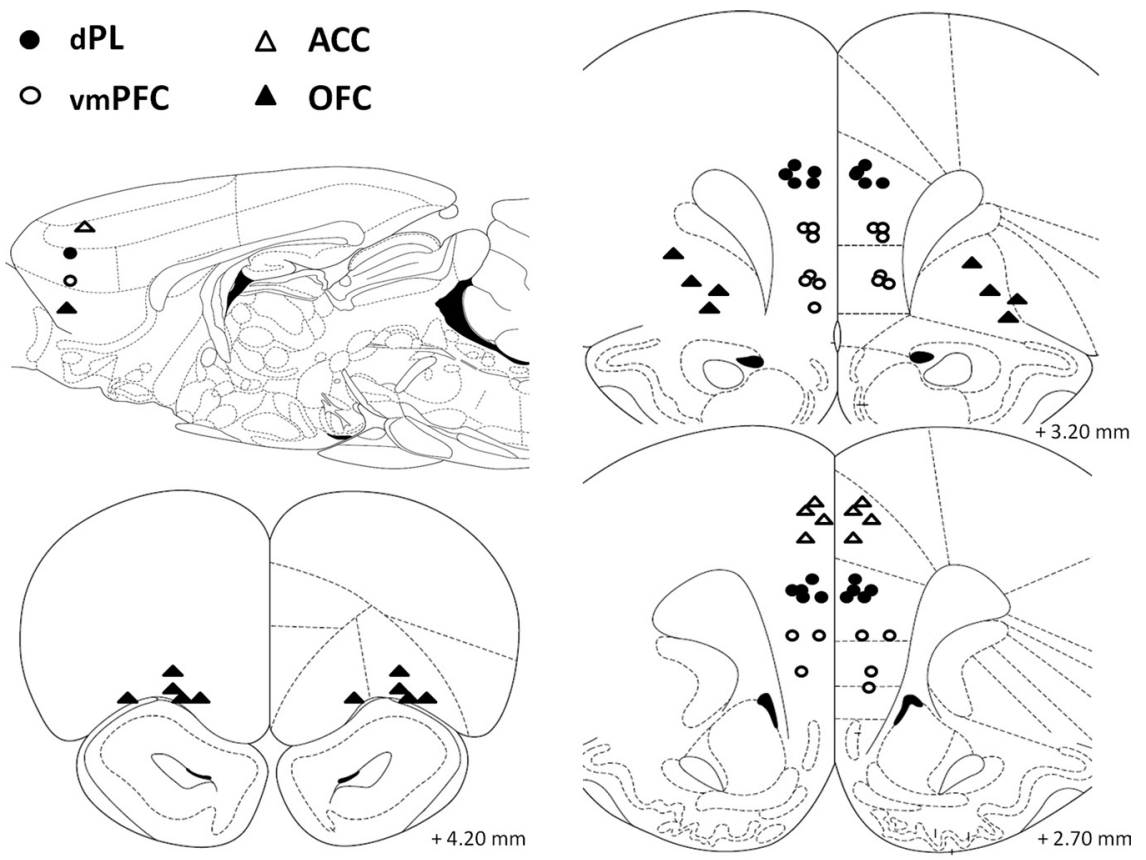

Figure 2. Schematic representation of the position of the injector tips in experiment 1 (muscimol microinfusions; $0.5 \mu \mathrm{g} / 0.5 \mu \mathrm{l}$ per side) as revealed by histological analysis. The sagittal view approximately shows the areas targeted by injectors on the sagittal plane. Open triangles, $\mathrm{ACC}(n=4)$; filled circles, $\mathrm{dPL}(n=12)$; open circles, $\operatorname{vmPFC}(n=10)$; filled triangles, $0 \mathrm{FC}(n=9)$. Drawings adapted from Paxinos and Watson (1998).
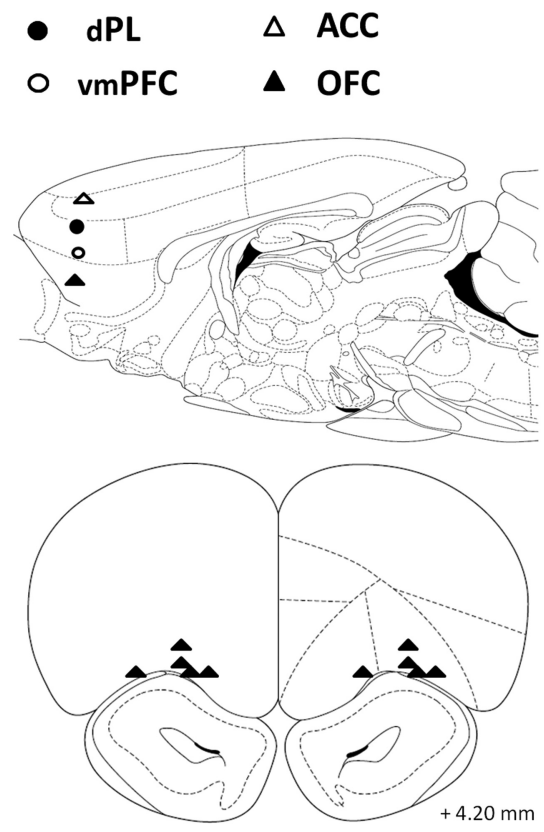

Figure 3. Schematic representation of the position of the injector tips in experiment 2 as revealed by histological analysis. The sagittal view approximately shows the areas targeted by atomoxetine $(0.1 \mu \mathrm{g} / 0.5 \mu \mathrm{l}$ per side) microinjections on the sagittal plane. Open triangles, ACC $(n=14)$; filled circles, dPL $(n=13)$; open circles, vmPFC $(n=13)$; filled triangles, $0 \mathrm{FC}(n=11)$. Drawings adapted from Paxinos and Watson (1998). neurotransmission by $\alpha$-flupenthixol infusions because it produces effects similar to those of DA depletion (Robbins et al., 1990; Naneix et al., 2009) and because it is devoid of unwanted side effects on feeding behavior (Park et al., 2002). Conversely, local infusion of $\alpha 2$-adrenergic agonists in dPL can potentially interfere with both NA and DA transmission. We used guanfacine, which preferentially binds to $\alpha 2 \mathrm{~A}$ adrenoceptor and which is less potent than other nonselective $\alpha 2$ agonists in decreasing DA 

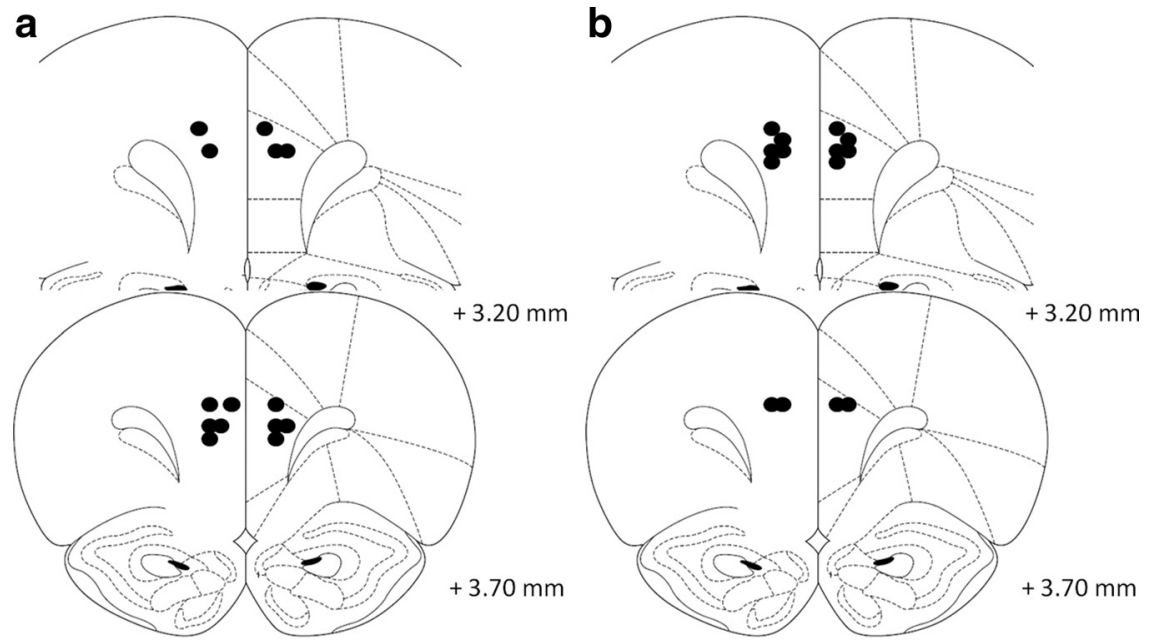

Figure 4. Schematic representation of the position of the injector tips in experiment 3 as revealed by histological analysis. Guanfacine (a) (0.005 $\mu \mathrm{g} / 0.5 \mu \mathrm{l}$ per side) and $\alpha$-flupenthixol (b) ( $15 \mu \mathrm{g} / 0.5 \mu$ l per side) were microinfused into the $\mathrm{PPL}(n=7$ for both). Drawings adapted from Paxinos and Watson (1998).
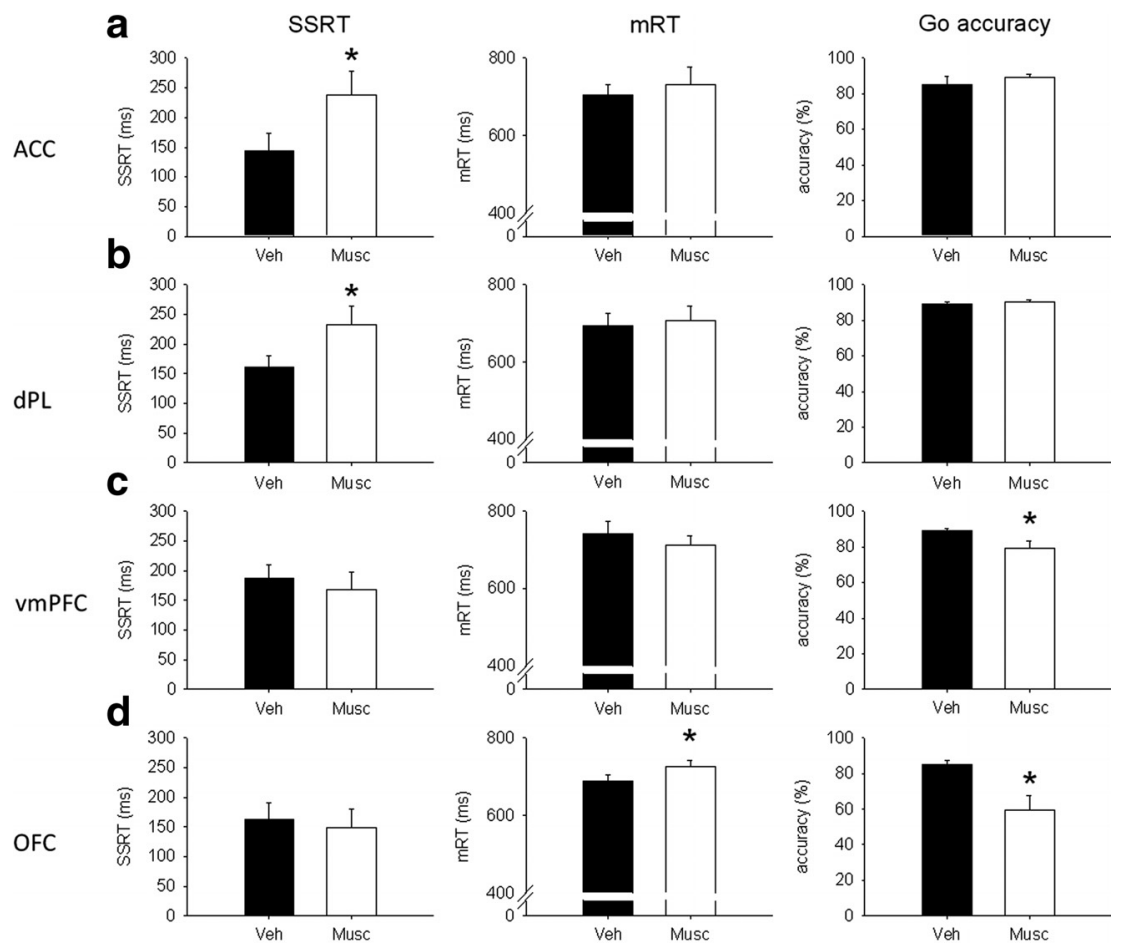

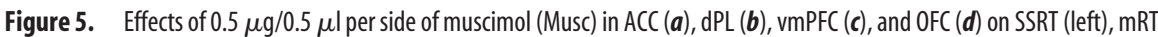
(middle), and go accuracy (right). Muscimol infused into the ACC or dPL prolonged SSRT without affecting go-related measures. The same drug infused into the vmPFC or OFC impaired go-related measures disrupting global performance on the task. In these conditions of very low go accuracy (OFC), SSRT estimates may not be reliable. Veh, Vehicle. ${ }^{*} p<0.05$.
Data analysis. Repeated-measures ANOVA was used for the data analysis, with drug and SSDs as within-subjects factors, followed by Fisher's least significant difference post hoc test when appropriate (Howell, 1997; Cardinal and Aitken, 2006). Mauchly's test was used to assess departures from sphericity. Significant interactions between drug and SSD for stop accuracy data were decomposed using the simple main effect (SME) analysis. Measures analyzed included SSRT, mRT, go accuracy, and stop accuracy. SSRT was estimated using the protocol described by Logan (1994). SSRTs from the two SSDs were averaged to give a single estimate for each rat, on each test session. SSRT and stop accuracy (i.e., percentage of stop trials in which the go response was correctly inhibited) were adjusted for the presence of omission errors on go trials to correct for the stop trials when an inhibition may not be attributed to a successful stop but accounted for by distraction. Adjustment was performed using the correction factor of Tannock et al. (1989): adjusted $p$ (inhibit $)=$ observed $p$ (inhibit $)-p($ omission) $/ 1-p$ (omission), where $p$ represents the probability of inhibiting or omitting the go response. However, differently from the SSRT, stop accuracy does not take into account changes in GoRT, and thus it may be more biased when these happen. Data were analyzed using SPSS 17.0 (SPSS). Graphs were plotted using SigmaPlot 8.0 (SPSS) to show group means, with error bars representing SEM. Asterisks indicate significant difference versus control condition, and the symbol \# indicates only a main effect of drug when there is no interaction between variables.

\section{Results}

\section{Histology}

Histological assessment revealed the position of the injector tips as represented schematically in Figures 2-4. Animals with injector placement outside intended areas or not performing according to the constraints of the "race model" (Logan, 1994) were removed from the analysis. The final group sizes were as follows: in experiment 1, ACC, 4; dPL, 10; vmPFC, 10; OFC, 9; in experiment 2, ACC, 14; $\mathrm{dPL}, 13$; vmPFC, 13; OFC, 11; in experiment 3, dPL, 7 guanfacine; and 7 $\alpha$-flupenthixol. Some of these animals were used in both experiments 1 and 2: OFC, 8; ACC, 3; and vmPFC, 3. release compared with NA (Scholtysik et al., 1975; Saameli et al., 1982; Nami et al., 1983; Ihalainen and Tanila, 2002), and thus may preferentially affect NA at the low dose used in the present experiment. Guanfacine (a generous gift from Pharmaceutics International) (Uhlén and Wikberg, 1991) was dissolved in sterile PBS and infused into the dPL at the dose of $0.005 \mu \mathrm{g} / 0.5 \mu \mathrm{l}$ per side. The mixed $\mathrm{D}_{1} / \mathrm{D}_{2}$ dopaminergic receptor antagonist $\alpha$-flupenthixol (Sigma) (Murrin, 1983) was dissolved in sterile PBS and infused into the dPL at the dose of $15 \mu \mathrm{g} / 0.5 \mu \mathrm{l}$ per side. Drug doses were chosen based on previous pilot experiments and published reports that used similar procedures (Broersen et al., 2000; Dunn and Killcross, 2006; Naneix et al., 2009).

\section{Experiment 1: effects of intra-PFC muscimol infusions}

ACC

Muscimol infusion in the ACC (Fig. $5 a$ ) significantly slowed SSRT $\left(F_{(1,3)}=10.8, p<0.05\right)$, whereas $\operatorname{mRT}\left(F_{(1,3)}=1.05\right.$, NS $)$ and go $\operatorname{accuracy}\left(F_{(1,3)}=0.95\right.$, NS) were not affected compared with vehicle infusion. Stop accuracy (see Fig. 7a) was significantly decreased by muscimol infusion $\left(F_{(1,3)}=58.9, p<0.01\right)$, and there was a significant interaction with SSD (drug $\times$ SSD $\left., F_{(2,6)}=6.69, p<0.05\right)$. SME analysis showed that stop accuracy was significantly decreased 
by muscimol infusion at $-300 \mathrm{~ms}\left(F_{(1,3)}=\right.$ $77.5, p<0.01)$ but not at $\mathrm{ZD}\left(F_{(1,3)}=2.51\right.$, NS) or $-100 \mathrm{~ms}\left(F_{(1,3)}=2.49\right.$, NS).

$d P L$

Muscimol infusion in animals with cannulae targeting the dPL (Fig. $5 b$ ) significantly prolonged SSRT $\left(F_{(1,9)}=8.9, p<\right.$ $0.05)$. There were no differences in $\mathrm{mRT}$ $\left(F_{(1,9)}=0.22\right.$, NS) or go accuracy $\left(F_{(1,9)}=\right.$ 4.16, NS). Stop accuracy (see Fig. $7 a$ ) was significantly decreased by muscimol $\left(F_{(1,9)}=13.7, p<0.01\right)$, but there was no significant interaction (drug $\times$ SSD, $F_{(2,18)}=2.9$, NS).

\section{$v m P F C$}

Bilateral muscimol infusion in vmPFC

(Fig. $5 c)$ did not affect SSRT $\left(F_{(1,9)}=0.98\right.$, NS) or $\operatorname{mRT}\left(F_{(1,9)}=\right.$ $1.37, \mathrm{NS})$. Go accuracy was significantly decreased after temporary inactivation of the $\operatorname{vmPFC}\left(F_{(1,9)}=7.92, p<0.05\right)$. Stop accuracy (see Fig. $7 a$ ) was not significantly different after muscimol infusion, but there was a significant interaction between the treatment and $\operatorname{SSD}\left(F_{(1,9)}=2.91\right.$, NS; drug $\times \operatorname{SSD}, F_{(2,18)}=7.36$, $p<0.01)$. SME analysis revealed that stop accuracy was lower after muscimol infusion only at $-300 \mathrm{~ms}\left(F_{(1,9)}=6.16, p<\right.$ $0.05)$. However, there was a trend toward a stop accuracy impairment after muscimol infusion at $\operatorname{ZD~}\left(F_{(1,9)}=5.03, p=0.052\right)$ and toward an improvement at $-100 \mathrm{~ms}\left(F_{(1,9)}=4.97, p=0.053\right)$.

OFC

Muscimol infusion in OFC (Fig. $5 d)$ did not affect SSRT $\left(F_{(1,8)}=\right.$ 0.17 , NS). The same treatment significantly increased $\mathrm{mRT}$ $\left(F_{(1,8)}=9.44, p<0.05\right)$. Moreover, go accuracy was so much impaired after muscimol infusion $\left(F_{(1,8)}=9.22, p<0.05\right)$ as to impede a clear interpretation of the SSRT data. There was no effect of drug on stop accuracy $\left(F_{(1,8)}=1.88\right.$, NS) (see Fig. $7 a$ ), but there was a significant interaction between treatment and SSD (drug $\left.\times \operatorname{SSD}, F_{(2,16)}=15.91, p<0.01\right)$. SME analysis showed that stop accuracy was higher at $-100 \mathrm{~ms}\left(F_{(1,8)}=10.31\right.$, $p<0.05)$ but not at the other SSDs $\left(\mathrm{ZD}, F_{(1,8)}=1.92\right.$, NS; -300 $\mathrm{ms}, F_{(1,8)}=1.51$, NS) after muscimol infusion. The increase in stop accuracy at $-100 \mathrm{~ms}$ is likely to be caused by the strong decrease in go accuracy. A similar pattern of results was obtained after infusion of a lower dose of muscimol $(0.05 \mu \mathrm{g} / 0.5 \mu \mathrm{l}$ per side) in the OFC during pilot experiments (data not shown).

\section{Experiment 2: effects of intra-PFC atomoxetine infusions \\ ACC}

Atomoxetine infusion $(0.1 \mu \mathrm{g} / 0.5 \mu \mathrm{l}$ per side $)$ into the ACC did not affect SSRT (Fig. $6 a)\left(F_{(1,13)}=0.57, \mathrm{NS}\right), \operatorname{mRT}\left(F_{(1,13)}=3.39\right.$, NS), go accuracy $\left(F_{(1,13)}=1.33\right.$, NS), or stop accuracy $\left(F_{(1,13)}=\right.$ 0.63 , NS; drug $\times \mathrm{SSD}, F_{(2,26)}=0.58$, NS) (Fig. $\left.7 b\right)$.

$d P L$

Infusion of atomoxetine into the dPL significantly speeded SSRT $\left(F_{(1,12)}=5.29, p<0.05\right)$ (Fig. $\left.6 b\right)$. There was no effect of atomoxetine on $\operatorname{mRT}\left(F_{(1,12)}=0.04\right.$, NS) or go accuracy $\left(F_{(1,12)}=\right.$ 0.002 , NS). There was a trend toward an improvement in stop accuracy in animals treated with atomoxetine $\left(F_{(1,12)}=4.4, p=\right.$ 0.058 ) (Fig. $7 b$ ) but no interaction between treatment and SSD $\left(\right.$ drug $\left.\times \mathrm{SSD}, F_{(2,24)}=1.35, \mathrm{NS}\right)$.

$v m P F C$

There was no effect of atomoxetine infusion in vmPFC on SSRT (Fig. 6c) $\left(F_{(1,12)}=0.36, \mathrm{NS}\right), \operatorname{mRT}\left(F_{(1,12)}=0.43, \mathrm{NS}\right)$, go accu-
$\operatorname{racy}\left(F_{(1,12)}=2.36, \mathrm{NS}\right)$, or stop accuracy $\left(F_{(1,12)}=0.002, \mathrm{NS}\right)$, although there was a trend toward a significant interaction between drug and SSD (drug $\times$ SSD, $\left.F_{(2,24)}=3.3, p=0.054\right)$ (Fig. 7b).

\section{OFC}

Atomoxetine infusion into the OFC significantly speeded SSRT (Fig. $6 d)\left(F_{(1,10)}=12.9, p<0.01\right)$ but did not change $\operatorname{mRT}\left(F_{(1,10)}=0.18\right.$, NS) or go accuracy $\left(F_{(1,10)}=0.11, \mathrm{NS}\right)$. Stop accuracy was not affected by atomoxetine infusion $\left(F_{(1,10)}=2.88\right.$, NS; drug $\times$ SSD, $F_{(2,20)}=2.61$, NS) (Fig. $\left.7 b\right)$.

\section{Experiment 3: effects of guanfacine and $\alpha$-flupenthixol infusions in $\mathrm{dPL}$}

Infusion of $0.005 \mu \mathrm{g} / 0.5 \mu \mathrm{l}$ per side of guanfacine into the $\mathrm{dPL}$ (Fig. 8a) significantly lengthened $\operatorname{SSRT}\left(F_{(1,6)}=23.27, p<0.01\right)$. The same treatment did not affect $\operatorname{mRT}\left(F_{(1,6)}=0.29\right.$, NS) or go $\operatorname{accuracy}\left(F_{(1,6)}=0.35\right.$, NS). Stop accuracy was significantly decreased by guanfacine infusion $\left(F_{(1,6)}=9.11, p<0.05\right)$ (Fig. 9), and there was an almost significant interaction between treatment and SSD (drug $\times$ SSD $\left., F_{(2,12)}=3.9, p=0.05\right)$. SME analysis showed that stop accuracy was not changed by the treatment at $\mathrm{ZD}\left(F_{(1,6)}=0.004, \mathrm{NS}\right)$ and decreased at $-300 \mathrm{~ms}\left(F_{(1,6)}=20.01\right.$, $p<0.01)$, and there was a trend toward an impairment at -100 ms, $\left(F_{(1,6)}=5.02, p=0.06\right)$.

$\alpha$-Flupenthixol ( $15 \mu \mathrm{g} / 0.5 \mu \mathrm{l}$ per side) infused into the dPL (Fig. $8 b)$ did not affect SSRT $\left(F_{(1,6)}=2.97, \mathrm{NS}\right)$. There was no significant effect on go accuracy $\left(F_{(1,6)}=0.29\right.$, NS) or stop accu$\operatorname{racy}\left(F_{(1,6)}=1.7, \mathrm{NS}\right.$; drug $\times \operatorname{SSD}, F_{(2,12)}=0.86$, NS) (Fig. 9). The only variable affected by $\alpha$-flupenthixol was the mRT, which was significantly increased by the treatment $\left(F_{(1,6)}=7.65, p<\right.$ $0.05)$.

\section{Discussion}

In the present study, we found that reversible inactivation of the rat ACC or dPL prolonged SSRT, impaired stop accuracy, but did not affect go-related measures. Moreover, our results indicate that the nonstimulant ADHD drug atomoxetine acts in the $\mathrm{dPL}$ and OFC to decrease impulsivity in the SST. Finally, local infusion of guanfacine, but not $\alpha$-flupenthixol, in the dPL produced effects opposite to those of atomoxetine infusion, suggestive of NE rather than DA effects.

Consistent with the present results, several studies have highlighted the importance of the rat $\mathrm{dmPFC}$ in response inhibition in a variety of tasks (Bari and Robbins, 2011). Lesion or inactivation of the dmPFC impairs rats' ability to await a trigger stimulus 


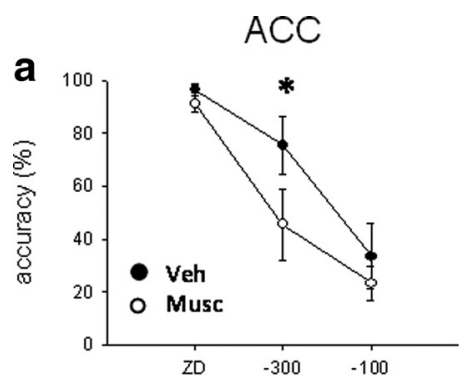

$\mathrm{dPL}$
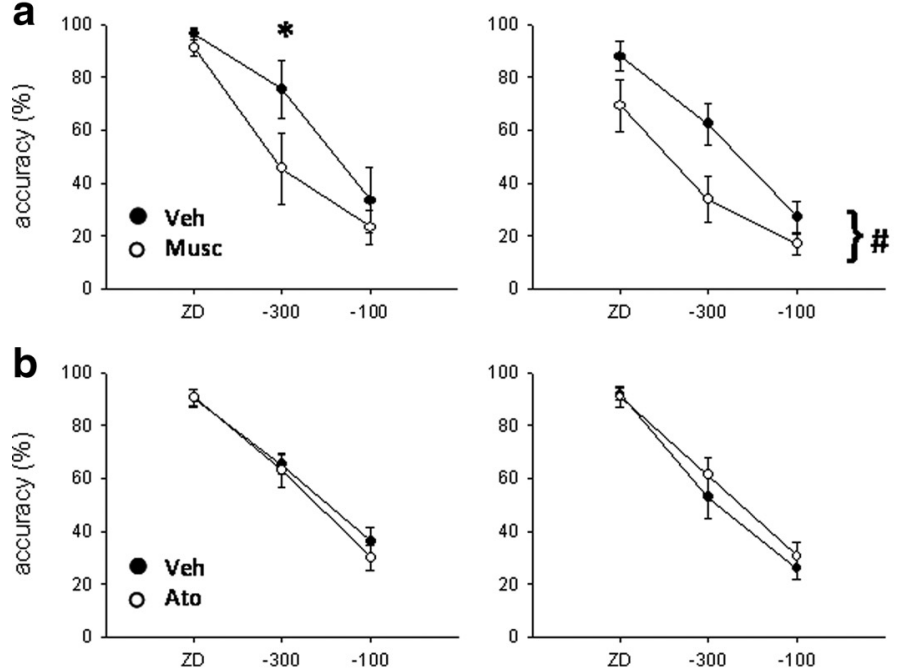

vmPFC
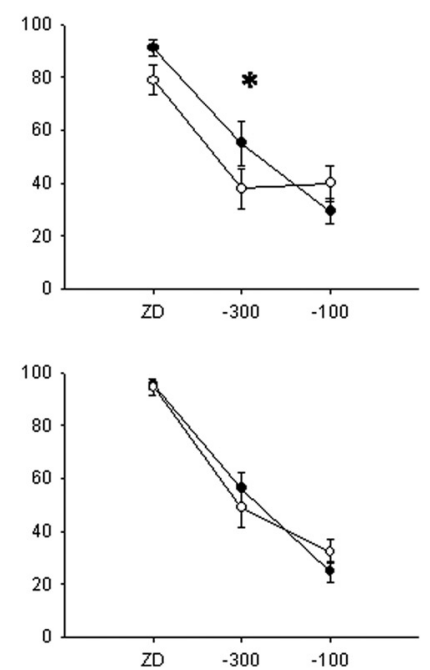

OFC
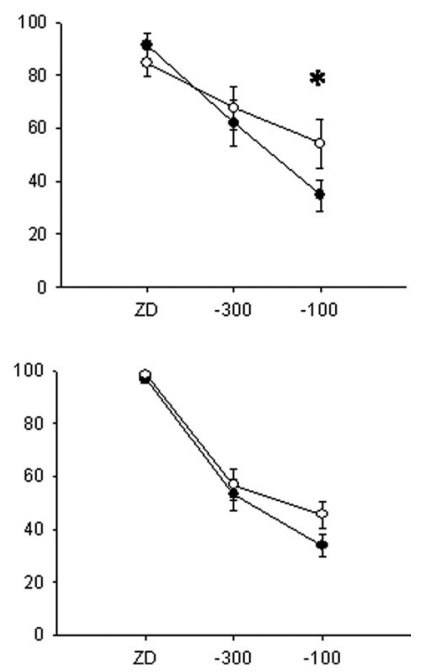

Figure 7. Effect of muscimol ( $\boldsymbol{a}$; Musc) and atomoxetine ( $\boldsymbol{b}$; Ato) infusions into the ACC, dPL, vmPFC, and OFC. Muscimol ( $0.5 \mu \mathrm{g} / 0.5 \mu \mathrm{l}$ per side) significantly impaired stop accuracy in ACC and $\mathrm{dPL}$. In this latter region, stop accuracy was decreased across SSDs, whereas in the former, decomposition of the interaction revealed a significant effect only at $-300 \mathrm{~ms}$. Effects in 0 FC and vmPFC are likely to be caused by the effect of the drug on go accuracy (Fig. 5). Atomoxetine ( $0.1 \mu \mathrm{g} / 0.5 \mu \mathrm{l}$ per side) did not affect significantly stop accuracy in any PFC subregion at the dose tested, suggesting that its effects are selective to the SSRT. Veh, Vehicle. ${ }^{*} p<0.05$, simple main effect analysis; ${ }^{\#} p<0.01$, main effect only.
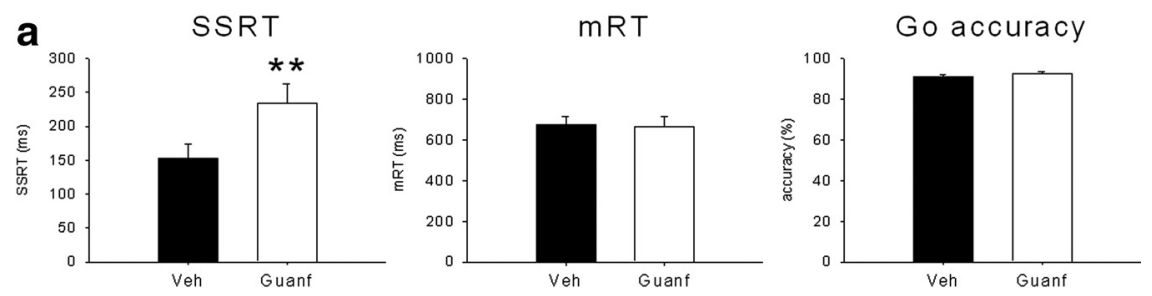

b
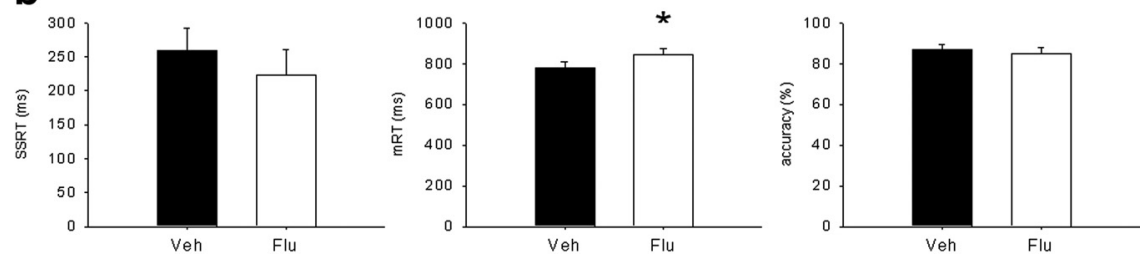

Figure 8. Effects of guanfacine ( $\boldsymbol{a}$; Guanf) and $\alpha$-flupenthixol ( $\boldsymbol{b}$; Flu) microinfusions into the dPL on SSRT, mRT, and go accuracy. The $\alpha 2 \mathrm{~A}$-adrenergic agonist guanfacine $(0.005 \mu \mathrm{g} / 0.5 \mu \mathrm{l}$ per side) selectively prolonged SSRT, whereas the mixed $D_{1} / D_{2}$ antagonist $\alpha$-flupenthixol ( $15 \mu \mathrm{g} / 0.5 \mu$ l per side) prolonged go reaction time, without any effect on stopping. Veh, Vehicle. ${ }^{*} p<0.05$ and ${ }^{* *} p<0.01$.
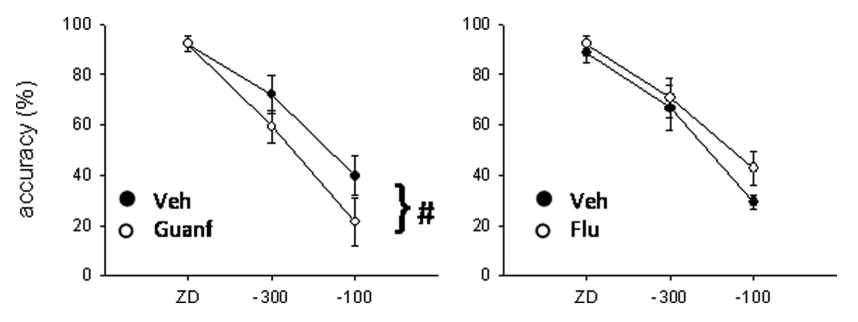

Figure 9. Effects of guanfacine (left; Guanf) and $\alpha$-flupenthixol (right; Flu) on stop accuracy. Guanfacine infusion ( $0.005 \mu \mathrm{g} / 0.5 \mu \mathrm{l}$ per side) significantly impaired stop accuracy, whereas $\alpha$-flupenthixol (15 $\mu \mathrm{g} / 0.5 \mu$ l per side) did not have any significant effect on this measure. Veh, Vehicle. ${ }^{\#} p<0.05$, main effect only.

before emitting a response (Broersen and Uylings, 1999; Risterucci et al., 2003; Narayanan et al., 2006). The present results demonstrate in addition that the dmPFC in the rat is also involved in the rapid cancellation of an already initiated action and thus implicated in reactive response inhibition over a much faster timescale.

The SSRT depends also on the speed at which the stop signal is encoded. Neurons in $\mathrm{dmPFC}$ selectively respond with phasic excitatory activity to infrequent, meaningful, and reward-predictive stimuli (Jodo et al., 2000), and transient inactivation of this area impairs the behavioral response to such stimuli (Ishikawa et al., 2008a,b). This evidence suggests a role for the rat dmPFC in redirecting the attention to the stop signal during SST performance. However, others have reported that the majority of $\mathrm{dmPFC}$ neurons are selectively involved in the inhibitory component of a task but not modulated by the attentional requirements (Narayanan and Laubach, 2006; Hayton et al., 2010), thus favoring the inhibitory hypothesis. More work is necessary to separate the attentional from the inhibitory component of SST performance.

Previous lesion studies did not find any impairment in SST performance after excitotoxic PL lesions (Eagle and Robbins, 2003b). Although a more extensive area was affected in that study, this discrepancy could be attributable to augmented sensitivity of the present, compared with the previous, paradigm or with possible functional recovery after the lesion. SST performance might be more sensitive to acute PFC inactivation, because other areas may compensate for the permanent loss of dmPFC contribution to response inhibition (Lomber, 1999; Martin and Ghez, 1999). Eagle et al. (2008b) demonstrated that excitotoxic lesions of the OFC prolong SSRT in rats. In the present study, temporary inactivation of the OFC disrupted general performance by producing large impairments in go accuracy and prolonging the go response. Under these conditions, SSRT estimates may not be accurate, thereby preventing firm conclusions concerning the contribution of the OFC to this measure. 
Blocking NE reuptake by systemic administration of atomoxetine improves stop-signal inhibition in both rats (Robinson et al., 2008) and humans (Chamberlain et al., 2006). On the contrary, increasing DA availability by blocking its reuptake (Bari et al., 2009) or by L-DOPA administration (Overtoom et al., 2003) does not affect SSRT, although intrastriatal DA antagonists do influence SST performance (Eagle et al., 2011). However, experiments that make use of systemic drug administration leave open important questions concerning the specific neural substrate and the neurochemical systems that mediate the observed behavioral effects (Robbins and Arnsten, 2009; Floresco and Jentsch, 2011); thus, experiments 2 and 3 addressed these issues.

We found that locally blocking NE reuptake in $\mathrm{APL}$ and OFC by atomoxetine microinfusions selectively speeded SSRT. These two discrete areas of the rat PFC possess bidirectional connections with the locus ceruleus (LC) (Zhu and Aston-Jones, 1996; Jodo et al., 1998) and may exert top-down control on the release of NE in forebrain areas (Arnsten and Goldman-Rakic, 1984; Robbins, 2005), facilitating the influence of cognitive processes on behavioral output (Usher et al., 1999; Aston-Jones and Cohen, 2005a). Thus, enhancing NE activity in PFC may render LC neurons more responsive to behaviorally relevant stimuli that trigger a sudden change in, or an interruption of, ongoing behavior (Aston-Jones and Cohen, 2005b; Bouret and Sara, 2005; Dayan and $\mathrm{Yu}, 2006)$. In turn, phasic NE release by LC neurons may enhance stimulus-evoked neural responsiveness in both sensory and motor areas (Foote and Morrison, 1987; Berridge and Waterhouse, 2003). In the SST, this would facilitate the processing of the stop signal, thus improving stopping performance.

Alternatively, or in addition, atomoxetine may exert its beneficial effects by enhancing the efficacy of frontal-basal ganglia networks for inhibitory control (Eagle and Baunez, 2010). This is consistent with tract-tracing studies that have shown that both OFC and dPL project to adjacent sectors of the striatum (Gabbott et al., 2005; Schilman et al., 2008) that are also implicated in response inhibition in rats (Eagle and Robbins, 2003a) and humans (Zandbelt and Vink, 2010).

The lack of effect of intra-ACC atomoxetine is consistent with the sparse noradrenergic innervation of this area (Morrison et al., 1979; Loughlin et al., 1982), as opposed to more caudal cingulate subregions that are heavily innervated by the LC (Heidbreder and Groenewegen, 2003). Atomoxetine had no effect also in the vmPFC, a region that projects to the ventral, but not dorsal, striatum (Gabbott et al., 2005) and that provides only limited input to the LC (Cedarbaum and Aghajanian, 1978; Luppi et al., 1995; Samuels and Szabadi, 2008). Moreover, vmPFC inactivation did not affect SSRT, confirming that this region is not directly implicated in SST response inhibition.

Blocking NE reuptake affects extracellular levels of both NE and DA in PFC (Tanda et al., 1997; Morón et al., 2002) as a result of the high affinity of the NE transporter for DA and the paucity of DA reuptake sites in this area (Ciliax et al., 1995; Sesack et al., 1998). Thus, although it has been shown that atomoxetine improves working memory performance via $\alpha 2$-adrenergic and DA $D_{1}$ receptors (Gamo et al., 2010), the neurochemical specificity of its effects on response inhibition has not yet been determined (Floresco and Jentsch, 2011). To better define the likely relative contributions of NE and DA in PFC to SST performance, we microinfused the $\alpha 2 \mathrm{~A}$-adrenergic agonist guanfacine or the $\mathrm{D}_{1} / \mathrm{D}_{2}$ dopaminergic antagonist $\alpha$-flupenthixol into the rat $\mathrm{dPL}$, thus interfering with NA and DA neurotransmission, respectively. Guanfacine microinfusions selectively prolonged SSRT, which is consistent with studies showing that PFC infusions of $\alpha 2$-adrenergic agonists decrease extracellular NE levels (van Veldhuizen et al., 1993; Dalley and Stanford, 1995). A possible effect of guanfacine on PFC DA cannot be completely excluded (Gresch et al., 1995). However, against this view, $\alpha$-flupenthixol infusions did not affect SSRT but slowed the go response similar to the effects observed after systemic injections (Eagle et al., 2007). These findings support the suggestion that it is the speed of the go rather than the stop response that is under control of dopaminergic neurotransmission within the PFC (Eagle et al., 2008a).

The effects of centrally infused guanfacine on SSRT are consistent with previous studies using a systemic route of administration in humans (Muller et al., 2005) or rats (Bari et al., 2009). Intra-dPL guanfacine may impair stopping by either activating postsynaptic $\alpha 2$ receptors on pyramidal neurons or its action at presynaptic $\alpha 2$ autoreceptors located on noradrenergic terminals (Aoki et al., 1998). In the first case, the net effect would be the suppression of glutamate synaptic transmission (Ji et al., 2008), whereas in the latter, guanfacine would cause a decrease of NE and DA release from presynaptic terminals (Devoto et al., 2001). However, the dissociable effects of guanfacine and $\alpha$-flupenthixol infusions on stop- and go-related measures respectively, suggest a selective action of guanfacine on noradrenergic neurotransmission at the dose used here.

Guanfacine produces beneficial effects on working memory (Arnsten and Pliszka, 2011) in tasks possibly necessitating a different level of PFC activation compared with the SST. For example, working memory tasks require subjects to attenuate the response to potentially distracting stimuli, and $\alpha 2$-adrenergic agonists might accomplish this by decreasing neural responses to isolated excitatory inputs (distractors) through inhibition of hyperpolarization-activated/cyclic nucleotide channels, while strengthening network responsiveness to recurrent excitation (Carr et al., 2007; Wang et al., 2007). Conversely, increasing NE availability by $\alpha 2$ antagonists might make neurons more responsive to unpredictable salient stimuli, improving performance in the SST and in other tasks requiring not a narrow attentional focus (cf., Milstein et al., 2007; Bondi et al., 2010; Gamo et al., 2010) but flexible attentional shifts (Devauges and Sara, 1990; Lapiz and Morilak, 2006).

In summary, this study demonstrated that, as in humans (Aron et al., 2007; Duann et al., 2009), multiple prefrontal loci are involved in SST performance and in the effects of atomoxetine on response inhibition in the rat. Thus, atomoxetine in PFC selectively improved SSRT possibly by enhancing the top-down influence of prefrontal regions on subcortical structures. These effects are likely mediated via noradrenergic mechanisms, because interfering primarily with NE, but not DA, neurotransmission prolonged SSRT, whereas the newly identified role of the ACC in response inhibition might be modulated differently. The present findings significantly advance our understanding of the neural circuitry and neurochemical systems implicated in response inhibition in the rat, which is important for the translational investigation of pathologies characterized by impulsivity.

\section{References}

Aoki C, Venkatesan C, Go CG, Forman R, Kurose H (1998) Cellular and subcellular sites for noradrenergic action in the monkey dorsolateral prefrontal cortex as revealed by the immunocytochemical localization of noradrenergic receptors and axons. Cereb Cortex 8:269-277.

Arnsten AF, Goldman-Rakic PS (1984) Selective prefrontal cortical projections to the region of the locus coeruleus and raphe nuclei in the rhesus monkey. Brain Res 306:9-18. 
Arnsten AF, Pliszka SR (2011) Catecholamine influences on prefrontal cortical function: relevance to treatment of attention deficit/hyperactivity disorder and related disorders. Pharmacol Biochem Behav. Advanced online publication. Retrieved May 26, 2011. doi:10.1016/j.pbb.2011.01.020.

Aron AR, Robbins TW, Poldrack RA (2004) Inhibition and the right inferior frontal cortex. Trends Cogn Sci 8:170-177.

Aron AR, Behrens TE, Smith S, Frank MJ, Poldrack RA (2007) Triangulating a cognitive control network using diffusion-weighted magnetic resonance imaging (MRI) and functional MRI. J Neurosci 27:3743-3752.

Aston-Jones G, Cohen JD (2005a) Adaptive gain and the role of the locus coeruleus-norepinephrine system in optimal performance. J Comp Neurol 493:99-110.

Aston-Jones G, Cohen JD (2005b) An integrative theory of locus coeruleusnorepinephrine function: adaptive gain and optimal performance. Annu Rev Neurosci 28:403-450.

Band GP, van der Molen MW, Logan GD (2003) Horse-race model simulations of the stop-signal procedure. Acta Psychol (Amst) 112:105-142.

Bari A, Robbins TW (2011) Animal models of ADHD. Curr Top Behav Neurosci 7:149-185.

Bari A, Eagle DM, Theobald DE, Robbins TW (2007) Role of dorso-medial prefrontal cortex in behavioural inhibition in rats. Soc Neurosci Abstr 33:741.13.

Bari A, Eagle DM, Mar AC, Robinson ES, Robbins TW (2009) Dissociable effects of noradrenaline, dopamine, and serotonin uptake blockade on stop task performance in rats. Psychopharmacology 205:273-283.

Berridge CW, Waterhouse BD (2003) The locus coeruleus-noradrenergic system: modulation of behavioral state and state-dependent cognitive processes. Brain Res Brain Res Rev 42:33-84.

Bondi CO, Jett JD, Morilak DA (2010) Beneficial effects of desipramine on cognitive function of chronically stressed rats are mediated by alpha1adrenergic receptors in medial prefrontal cortex. Prog Neuropsychopharmacol Biol Psychiatry 34:913-923.

Bouret S, Sara SJ (2005) Network reset: a simplified overarching theory of locus coeruleus noradrenaline function. Trends Neurosci 28:574-582.

Broersen LM, Uylings HB (1999) Visual attention task performance in Wistar and Lister hooded rats: response inhibition deficits after medial prefrontal cortex lesions. Neuroscience 94:47-57.

Broersen LM, Abbate F, Feenstra MG, de Bruin JP, Heinsbroek RP, Olivier B (2000) Prefrontal dopamine is directly involved in the anxiogenic interoceptive cue of pentylenetetrazol but not in the interoceptive cue of chlordiazepoxide in the rat. Psychopharmacology (Berl) 149:366-376.

Bymaster FP, Katner JS, Nelson DL, Hemrick-Luecke SK, Threlkeld PG, Heiligenstein JH, Morin SM, Gehlert DR, Perry KW (2002) Atomoxetine increases extracellular levels of norepinephrine and dopamine in prefrontal cortex of rat: a potential mechanism for efficacy in attention deficit/ hyperactivity disorder. Neuropsychopharmacology 27:699-711.

Cardinal RN, Aitken MRF, eds (2006) ANOVA for the behavioural sciences researcher. Hillsdale, NJ: Erlbaum.

Carr DB, Andrews GD, Glen WB, Lavin A (2007) alpha2-Noradrenergic receptors activation enhances excitability and synaptic integration in rat prefrontal cortex pyramidal neurons via inhibition of HCN currents. J Physiol 584:437-450.

Cedarbaum JM, Aghajanian GK (1978) Afferent projections to the rat locus coeruleus as determined by a retrograde tracing technique. J Comp Neurol 178:1-16.

Chamberlain SR, Müller U, Blackwell AD, Clark L, Robbins TW, Sahakian BJ (2006) Neurochemical modulation of response inhibition and probabilistic learning in humans. Science 311:861-863.

Chamberlain SR, Del Campo N, Dowson J, Müller U, Clark L, Robbins TW, Sahakian BJ (2007) Atomoxetine improved response inhibition in adults with attention deficit/hyperactivity disorder. Biol Psychiatry 62:977-984.

Chamberlain SR, Hampshire A, Müller U, Rubia K, Del Campo N, Craig K, Regenthal R, Suckling J, Roiser JP, Grant JE, Bullmore ET, Robbins TW, Sahakian BJ (2009) Atomoxetine modulates right inferior frontal activation during inhibitory control: a pharmacological functional magnetic resonance imaging study. Biol Psychiatry 65:550-555.

Chambers CD, Bellgrove MA, Stokes MG, Henderson TR, Garavan H, Robertson IH, Morris AP, Mattingley JB (2006) Executive "brake failure" following deactivation of human frontal lobe. J Cogn Neurosci 18:444-455.
Ciliax BJ, Heilman C, Demchyshyn LL, Pristupa ZB, Ince E, Hersch SM, Niznik HB, Levey AI (1995) The dopamine transporter: immunochemical characterization and localization in brain. J Neurosci 15:1714-1723.

Corcoran KA, Maren S (2001) Hippocampal inactivation disrupts contextual retrieval of fear memory after extinction. J Neurosci 21:1720-1726.

Dalley JW, Stanford SC (1995) Contrasting effects of the imidazol(in)e alpha 2-adrenoceptor agonists, medetomidine, clonidine and UK 14,304 on extraneuronal levels of noradrenaline in the rat frontal cortex: evaluation using in vivo microdialysis and synaptosomal uptake studies. Br J Pharmacol 114:1717-1723.

Dayan P, Yu AJ (2006) Phasic norepinephrine: a neural interrupt signal for unexpected events. Network 17:335-350.

Devauges V, Sara SJ (1990) Activation of the noradrenergic system facilitates an attentional shift in the rat. Behav Brain Res 39:19-28.

Devoto P, Flore G, Pani L, Gessa GL (2001) Evidence for co-release of noradrenaline and dopamine from noradrenergic neurons in the cerebral cortex. Mol Psychiatry 6:657-664.

Duann JR, Ide JS, Luo X, Li CS (2009) Functional connectivity delineates distinct roles of the inferior frontal cortex and presupplementary motor area in stop signal inhibition. J Neurosci 29:10171-10179.

Dunn MJ, Killcross S (2006) Differential attenuation of d-amphetamine-induced disruption of conditional discrimination performance by dopamine and serotonin antagonists. Psychopharmacology (Berl) 188:183-192.

Eagle DM, Baunez C (2010) Is there an inhibitory-response-control system in the rat? Evidence from anatomical and pharmacological studies of behavioral inhibition. Neurosci Biobehav Rev 34:50-72.

Eagle DM, Robbins TW (2003a) Inhibitory control in rats performing a stop-signal reaction-time task: effects of lesions of the medial striatum and d-amphetamine. Behav Neurosci 117:1302-1317.

Eagle DM, Robbins TW (2003b) Lesions of the medial prefrontal cortex or nucleus accumbens core do not impair inhibitory control in rats performing a stop-signal reaction time task. Behav Brain Res 146:131-144.

Eagle DM, Tufft MR, Goodchild HL, Robbins TW (2007) Differential effects of modafinil and methylphenidate on stop-signal reaction time task performance in the rat, and interactions with the dopamine receptor antagonist cis-flupenthixol. Psychopharmacology (Berl) 192:193-206.

Eagle DM, Bari A, Robbins TW (2008a) The neuropsychopharmacology of action inhibition: cross-species translation of the stop-signal and go/ no-go tasks. Psychopharmacology 199:439-456.

Eagle DM, Baunez C, Hutcheson DM, Lehmann O, Shah AP, Robbins TW (2008b) Stop-signal reaction-time task performance: role of prefrontal cortex and subthalamic nucleus. Cereb Cortex 18:178-188.

Eagle DM, Wong JC, Allan ME, Mar AC, Theobald DE, Robbins TW (2011) Contrasting roles for dopamine $\mathrm{D}_{1}$ - and $\mathrm{D}_{2}$-receptor subtypes in the dorsomedial striatum but not the nucleus accumbens core during behavioral inhibition in the stop-signal task in rats. J Neurosci 31:7349-7356.

Easton N, Marshall F, Fone K, Marsden C (2007) Atomoxetine produces changes in cortico-basal thalamic loop circuits: assessed by phMRI BOLD contrast. Neuropharmacology 52:812-826.

Faraone SV, Biederman J, Spencer T, Michelson D, Adler L, Reimherr F, Glatt SJ (2005) Efficacy of atomoxetine in adult attention-deficit/hyperactivity disorder: a drug-placebo response curve analysis. Behav Brain Funct $1: 16$.

Feil J, Sheppard D, Fitzgerald PB, Yücel M, Lubman DI, Bradshaw JL (2010) Addiction, compulsive drug seeking, and the role of frontostriatal mechanisms in regulating inhibitory control. Neurosci Biobehav Rev $35: 248-275$.

Floresco SB, Jentsch JD (2011) Pharmacological enhancement of memory and executive functioning in laboratory animals. Neuropsychopharmacology 36:227-250.

Foote SL, Morrison JH (1987) Extrathalamic modulation of cortical function. Annu Rev Neurosci 10:67-95.

Gabbott PL, Warner TA, Jays PR, Salway P, Busby SJ (2005) Prefrontal cortex in the rat: projections to subcortical autonomic, motor, and limbic centers. J Comp Neurol 492:145-177.

Gamo NJ, Wang M, Arnsten AF (2010) Methylphenidate and atomoxetine enhance prefrontal function through alpha2-adrenergic and dopamine D1 receptors. J Am Acad Child Adolesc Psychiatry 49:1011-1023.

Gresch PJ, Sved AF, Zigmond MJ, Finlay JM (1995) Local influence of endogenous norepinephrine on extracellular dopamine in rat medial prefrontal cortex. J Neurochem 65:111-116. 
Hayton SJ, Lovett-Barron M, Dumont EC, Olmstead MC (2010) Targetspecific encoding of response inhibition: increased contribution of AMPA to NMDA receptors at excitatory synapses in the prefrontal cortex. J Neurosci 30:11493-11500.

Heidbreder CA, Groenewegen HJ (2003) The medial prefrontal cortex in the rat: evidence for a dorso-ventral distinction based upon functional and anatomical characteristics. Neurosci Biobehav Rev 27:555-579.

Hoover WB, Vertes RP (2007) Anatomical analysis of afferent projections to the medial prefrontal cortex in the rat. Brain Struct Funct 212:149-179.

Howell DC, ed (1997) Statistical methods for psychology, Ed 4. Belmont, CA: Duxbury.

Ihalainen JA, Tanila H (2002) In vivo regulation of dopamine and noradrenaline release by alpha2A-adrenoceptors in the mouse prefrontal cortex. Eur J Neurosci 15:1789-1794.

Ishikawa A, Ambroggi F, Nicola SM, Fields HL (2008a) Contributions of the amygdala and medial prefrontal cortex to incentive cue responding. Neuroscience 155:573-584.

Ishikawa A, Ambroggi F, Nicola SM, Fields HL (2008b) Dorsomedial prefrontal cortex contribution to behavioral and nucleus accumbens neuronal responses to incentive cues. J Neurosci 28:5088-5098.

Ji XH, Ji JZ, Zhang H, Li BM (2008) Stimulation of alpha2-adrenoceptors suppresses excitatory synaptic transmission in the medial prefrontal cortex of rat. Neuropsychopharmacology 33:2263-2271.

Jodo E, Chiang C, Aston-Jones G (1998) Potent excitatory influence of prefrontal cortex activity on noradrenergic locus coeruleus neurons. Neuroscience 83:63-79.

Jodo E, Suzuki Y, Kayama Y (2000) Selective responsiveness of medial prefrontal cortex neurons to the meaningful stimulus with a low probability of occurrence in rats. Brain Res 856:68-74.

Kim J, Ragozzino ME (2005) The involvement of the orbitofrontal cortex in learning under changing task contingencies. Neurobiol Learn Mem $83: 125-133$

Lapiz MD, Morilak DA (2006) Noradrenergic modulation of cognitive function in rat medial prefrontal cortex as measured by attentional set shifting capability. Neuroscience 137:1039-1049.

Lipszyc J, Schachar R (2010) Inhibitory control and psychopathology: a meta-analysis of studies using the stop signal task. J Int Neuropsychol Soc 16:1064-1076.

Logan GD (1994) On the ability to inhibit thought and action. A users' guide to the stop signal paradigm. In: Inhibitory processes in attention, memory and language. (Dagenbach D, Carr TH, eds), pp 189-236. San Diego: Academic.

Lomber SG (1999) The advantages and limitations of permanent or reversible deactivation techniques in the assessment of neural function. J Neurosci Methods 86:109-117.

Loughlin SE, Foote SL, Fallon JH (1982) Locus coeruleus projections to cortex: topography, morphology and collateralization. Brain Res Bull 9:287-294.

Luppi PH, Aston-Jones G, Akaoka H, Chouvet G, Jouvet M (1995) Afferent projections to the rat locus coeruleus demonstrated by retrograde and anterograde tracing with cholera-toxin B subunit and Phaseolus vulgaris leucoagglutinin. Neuroscience 65:119-160.

Martin JH, Ghez C (1999) Pharmacological inactivation in the analysis of the central control of movement. J Neurosci Methods 86:145-159.

Milstein JA, Lehmann O, Theobald DE, Dalley JW, Robbins TW (2007) Selective depletion of cortical noradrenaline by anti-dopamine betahydroxylase-saporin impairs attentional function and enhances the effects of guanfacine in the rat. Psychopharmacology (Berl) 190:51-63.

Morón JA, Brockington A, Wise RA, Rocha BA, Hope BT (2002) Dopamine uptake through the norepinephrine transporter in brain regions with low levels of the dopamine transporter: evidence from knock-out mouse lines. J Neurosci 22:389-395.

Morrison JH, Molliver ME, Grzanna R, Coyle JT (1979) Noradrenergic innervation patterns in three regions of medial cortex: an immunofluorescence characterization. Brain Res Bull 4:849-857.

Muller U, Clark L, Lam ML, Moore RM, Murphy CL, Richmond NK, Sandhu RS, Wilkins IA, Menon DK, Sahakian BJ, Robbins TW (2005) Lack of effects of guanfacine on executive and memory functions in healthy male volunteers. Psychopharmacology (Berl) 182:205-213.

Murrin LC (1983) Characteristics of 3H-cis-flupenthixol binding in rat striatum. Life Sci 33:2179-2186.

Nami R, Bianchini C, Fiorella G, Chierichetti SM, Gennari C (1983) Com- parison of effects of guanfacine and clonidine on blood pressure, heart rate, urinary catecholamines, and cyclic nucleotides during and after administration to patients with mild to moderate hypertension. J Cardiovasc Pharmacol 5:546-551.

Naneix F, Marchand AR, Di Scala G, Pape JR, Coutureau E (2009) A role for medial prefrontal dopaminergic innervation in instrumental conditioning. J Neurosci 29:6599-6606.

Narayanan NS, Laubach M (2006) Top-down control of motor cortex ensembles by dorsomedial prefrontal cortex. Neuron 52:921-931.

Narayanan NS, Horst NK, Laubach M (2006) Reversible inactivations of rat medial prefrontal cortex impair the ability to wait for a stimulus. Neuroscience 139:865-876.

Overtoom CC, Verbaten MN, Kemner C, Kenemans JL, van Engeland H, Buitelaar JK, van der Molen MW, van der Gugten J, Westenberg H, Maes RA, Koelega HS (2003) Effects of methylphenidate, desipramine, and L-dopa on attention and inhibition in children with attention deficit hyperactivity disorder. Behav Brain Res 145:7-15.

Park WK, Bari AA, Jey AR, Anderson SM, Spealman RD, Rowlett JK, Pierce RC (2002) Cocaine administered into the medial prefrontal cortex reinstates cocaine-seeking behavior by increasing AMPA receptor-mediated glutamate transmission in the nucleus accumbens. J Neurosci 22:29162925.

Pattij T, Vanderschuren LJ (2008) The neuropharmacology of impulsive behaviour. Trends Pharmacol Sci 29:192-199.

Paxinos G, Watson C (1998) The rat brain in stereotaxic coordinates, Ed 2. Sidney: Academic.

Ragozzino ME, Rozman S (2007) The effect of rat anterior cingulate inactivation on cognitive flexibility. Behav Neurosci 121:698-706.

Risterucci C, Terramorsi D, Nieoullon A, Amalric M (2003) Excitotoxic lesions of the prelimbic-infralimbic areas of the rodent prefrontal cortex disrupt motor preparatory processes. Eur J Neurosci 17:1498-1508.

Robbins TW (2005) Controlling stress: how the brain protects itself from depression. Nat Neurosci 8:261-262.

Robbins TW, Arnsten AF (2009) The neuropsychopharmacology of frontoexecutive function: monoaminergic modulation. Annu Rev Neurosci 32:267-287.

Robbins TW, Giardini V, Jones GH, Reading P, Sahakian BJ (1990) Effects of dopamine depletion from the caudate-putamen and nucleus accumbens septi on the acquisition and performance of a conditional discrimination task. Behav Brain Res 38:243-261.

Robinson ES, Eagle DM, Mar AC, Bari A, Banerjee G, Jiang X, Dalley JW, Robbins TW (2008) Similar effects of the selective noradrenaline reuptake inhibitor atomoxetine on three distinct forms of impulsivity in the rat. Neuropsychopharmacology 33:1028-1037.

Saameli K, Jerie P, Scholtysik G (1982) Guanfacine and other centrally acting drugs in antihypertensive therapy; pharmacological and clinical aspects. Clin Exp Hypertens A 4:209-219.

Samuels ER, Szabadi E (2008) Functional neuroanatomy of the noradrenergic locus coeruleus: its roles in the regulation of arousal and autonomic function. I. Principles of functional organisation. Curr Neuropharmacol 6:235-253.

Schilman EA, Uylings HB, Galis-de Graaf Y, Joel D, Groenewegen HJ (2008) The orbital cortex in rats topographically projects to central parts of the caudate-putamen complex. Neurosci Lett 432:40-45.

Scholtysik G, Lauener H, Eichenberger E, Bürki H, Salzmann R, Müller-Schweinitzer E, Waite R (1975) Pharmacological actions of the antihypertensive agent $\mathrm{N}$-amidino-2-(2,6-dichlorophenyl)acetamide hydrochloride (BS 100-141). Arzneimittelforschung 25:1483-1491.

Sesack SR, Hawrylak VA, Guido MA, Levey AI (1998) Cellular and subcellular localization of the dopamine transporter in rat cortex. Adv Pharmacol 42:171-174.

Souza MM, Mello e Souza T, Vinadé ER, Rodrigues C, Choi HK, Dedavid e Silva TL, Medina JH, Izquierdo I (2002) Effects of posttraining treatments in the posterior cingulate cortex on short- and long-term memory for inhibitory avoidance in rats. Neurobiol Learn Mem 77:202-210.

Tanda G, Pontieri FE, Frau R, Di Chiara G (1997) Contribution of blockade of the noradrenaline carrier to the increase of extracellular dopamine in the rat prefrontal cortex by amphetamine and cocaine. Eur J Neurosci 9:2077-2085.

Tannock R, Schachar RJ, Carr RP, Chajczyk D, Logan GD (1989) Effects of methylphenidate on inhibitory control in hyperactive children. J Abnorm Child Psychol 17:473-491. 
Uhlén S, Wikberg JE (1991) Delineation of rat kidney alpha 2A- and alpha 2B-adrenoceptors with [3H]RX821002 radioligand binding: computer modelling reveals that guanfacine is an alpha $2 \mathrm{~A}$-selective compound. Eur J Pharmacol 202:235-243.

Usher M, Cohen JD, Servan-Schreiber D, Rajkowski J, Aston-Jones G (1999) The role of locus coeruleus in the regulation of cognitive performance. Science 283:549-554.

van Duuren E, van der Plasse G, van der Blom R, Joosten RN, Mulder AB, Pennartz CM, Feenstra MG (2007) Pharmacological manipulation of neuronal ensemble activity by reverse microdialysis in freely moving rats: a comparative study of the effects of tetrodotoxin, lidocaine, and muscimol. J Pharmacol Exp Ther 323:61-69.

van Veldhuizen MJ, Feenstra MG, Heinsbroek RP, Boer GJ (1993) In vivo microdialysis of noradrenaline overflow: effects of alpha-adrenoceptor agonists and antagonists measured by cumulative concentrationresponse curves. Br J Pharmacol 109:655-660.

Vertes RP (2006) Interactions among the medial prefrontal cortex, hippocampus and midline thalamus in emotional and cognitive processing in the rat. Neuroscience 142:1-20.

Wang M, Ramos BP, Paspalas CD, Shu Y, Simen A, Duque A, Vijayraghavan S, Brennan A, Dudley A, Nou E, Mazer JA, McCormick DA, Arnsten AF (2007) Alpha2A-adrenoceptors strengthen working memory networks by inhibiting cAMP-HCN channel signaling in prefrontal cortex. Cell 129:397-410.

Zandbelt BB, Vink M (2010) On the role of the striatum in response inhibition. PLoS One 5:e13848.

Zhu Y, Aston-Jones G (1996) The medial prefrontal cortex prominently innervates a peri-locus coeruleus dendritic zone in the rat. Soc Neurosci Abstr 22:601. 